\title{
PHOTOINDUCED INTRAMOLECULAR ELECTRON-TRANSFER OF SUBSTITUTED BENZOATE ESTERS OF 9-ANTHRACENEMETHANOL IN METHANOL*
}

\author{
M.D.P. DE COSTA, P.K. CUMARANATUNGA and K.A.D. SRIYANI MALLIKA \\ Department of Chemistry, University of Colombo, Colombo.
}

(Received: 24 September 1996; accepted: 02 May 1997)

\begin{abstract}
The photoinduced intramolecular electron transfer is a complex phenomena. The role of the solvent and the substituents on the chromophore are important in electron transfer. The higher dipole moment difference between the excited and ground states is direct evidence for such an intramolecular electron transfer. In this study six esters of 9-anthracene methanol were synthesised and characterised. The Stoke shifts in different solvents for three esters were measured and the dipole moment difference between the excited and ground states were estimated. The fluorescence quantum yields in methanol for all the esters were measured. The results are explained by the intramolcular electron transfer in the excited state. The esters where the two chromophores linked by $-\mathrm{CH}_{2} \mathrm{OCO}$-group makes the possible interaction of two chromophores in the excited state were studied. The driving force for the electron transfer is therefore relatively strong. The estimated electron transfer rates were correlated with Hammett $\sigma$-values with the reaction constant, $\rho=+1$.5. This is a strong evidence for the presence of intramolecular electron transfer in the excited state.
\end{abstract}

Key Words: 9-Anthracene methyl esters, Bichromophoretic compound, fluorescence, Hammett correlation, photoinduced electron-transfer, solvent effects.

\section{INTRODUCTION}

The photoinduced electron transfer (PIET) has received much attention during the past two decades. There are several reviews ${ }^{1}$ and books ${ }^{2}$ published. The intramolecular PIET, however becomes attractive to the scientist, since it is the basic mechanism of biological and chemical - energy conversion processes. Recently there have been many articles ${ }^{3}$ published in this field. On electronic excitation of a molecule, the redistribution of charge and possible conformational changes which occur, can result in a net increase or decrease in the dipole moment of the system compared with that of the ground state. The knowledge of excited state charge distribution and dipole moments are important in understanding the photochemical processes. All the methods of determination of dipole moment of an excited state $\left(\mu_{\mathrm{e}}\right)$ are based on the position change of the spectral band caused by an electric field either external (electrochromism) or internal (solvalochromism). The determination of $\mu_{\mathrm{e}}$ by the method of solvalochromism is based on the shift of adsorption and/or fluorescence maxima in different solvents. The optimum results have been obtained by using the

* part of this work was presented at the 51st Annual session of the Sri Lanka Association for the Advancement of Science, 1995. 
model proposed by Bakshiev. ${ }^{4}$ Based on this model, several reports ${ }^{5}$ on fluorescent compounds have appeared in the literature. The dipole moment difference between the excited and ground state, $\left(\mu_{\mathrm{e}}-\mu_{\mathrm{g}}\right)$, is excellent evidence for the intramolecular photoinduced electron transfer processes.

Studies ${ }^{6}$ on the bichromophoretic compounds connected by $\sigma$-bonds have shown the formation of exciplexes. Most of these studies were done on the systems where the two chromophores are connected by a hydrocarbon chain; - $\left(\mathrm{CH}_{2}\right)_{\mathrm{n}}$-. Recently work carried out on the anthracene bichromophoretic compounds in various solvents show the formation of exciplexes. ${ }^{\top}$ The lower fluorescence quantum yields have been observed in the bichromophoretic compounds where the two chromophores are connected by the ester $-\mathrm{C}(=\mathrm{O}) \mathrm{OC}$ linkage. ${ }^{8}$ These esters are photostable and have shorter lifetimes. Moreover, these compounds give exciplexes emission at longer wavelengths. It was suggested that the exciplex is formed by intramolecular PIET from one chromophore to the other.

Our previous studies ${ }^{9}$ on the fluorescence quantum yields of 1-naphthalenemethyl benzoate, $\mathbf{3}$, have established intramolecular PIET from naphthalene chromophore to the benzoate chromophore. According to the Wellar equation $^{10}$ the free energy for the electron transfer $\left(\Delta \mathrm{G}_{\mathrm{ET}}\right)$ can be expressed in terms of oxidation potential of the naphthalene chromophore $\left(\mathrm{E}_{1 / 2}{ }^{\mathrm{ox}}\right)$ and reduction potential ( $E_{1,2}{ }^{\text {red}}$ ) of the benzoate chromophore along with the solvent contribution factor, $\mathrm{e}^{2 / 4 \pi \varepsilon r}$.

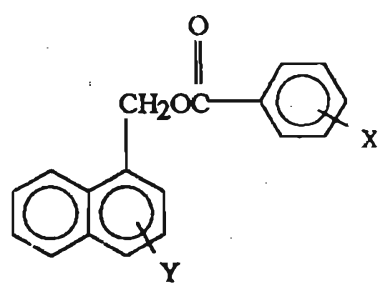

$$
\Delta G_{\mathrm{ET}}=\left(\mathrm{E}_{1 / 2}{ }^{\text {ox }}-\mathrm{E}_{\mathrm{i} / 2}{ }^{3} \text { red }-\mathrm{e}^{2} / 4 \pi \varepsilon \mathrm{r}\right)-\mathrm{E}_{0.0}
$$

Here $\mathrm{E}_{0,0}$ is the excited state energy of the compound. Therefore, the substituents attached to the two chromophores leads to the change of the above potentials and effects the electron - transfer rates. Studies carried out in our laboratories ${ }^{9}$ have established that electron donating groups attached to the naphthalene chromophore and electron withdrawing groups attached to the benzoate chromophore enhances the electron transfer rates. However, the weak fluorescence of these esters makes the estimation of electron transfer rates inaccurate. Therefore, in order to achieve greater accuracy we decided to carry out further studies with anthracene esters. In this paper we report the synthesis 
of the 9-anthracenemethyl acetate $\left(\mathrm{AnCH}_{2} \mathrm{OCOCH}_{3}\right), 1$, and 9-anthracenemethyl benzoate esters $\left(\mathrm{AnCH}_{2} \mathrm{OCOPh}\right), \mathbf{2 a - e}$, and their fluorescence measurements. We have also determined the $\left(\mu_{\mathrm{e}}-\mu_{\mathrm{g}}\right)$ for the compounds $1,2 \mathrm{a}$ and $2 \mathrm{c}$.

\section{METHODS AND MATERIALS}

Absorption spectra were obtained using a Jasco V - 560 UV/Visible spectrophotometer. GC/MS studies were done on a Hewlett Packard 5890 Series II Gas Chromatograph with column temperature programmed from $50^{\circ} \mathrm{C}$ to $250^{\circ} \mathrm{C}$ using a Hewlett Packard 5989A Mass spectrometer. Infrared spectra were recorded on a Jasco FT/IR - 5300 and are given in wave numbers $\left(\mathrm{cm}^{-1}\right)$. ${ }^{1} \mathrm{H}$ nmr spectra were obtained on Bruker ACF 200 instrument at $200 \mathrm{MHz}$ with chemical shifts relative to TMS. Fluorescence studies were done using a $\mathrm{RF}$ - 5000 Shimadzu Spectrofluorimeter at $25^{\circ} \mathrm{C}$, and spectra were corrected. All the chemicals except 9-anthracene methanol (Aldrich) were purchased from Fluka. All the solvents used in spectroscopic measurements are either of Analar grade or GP grade (purified by distillation).

General method for preparation of esters 1, 2a-e : The esters were prepared by a common method as outlined in Scheme 1.
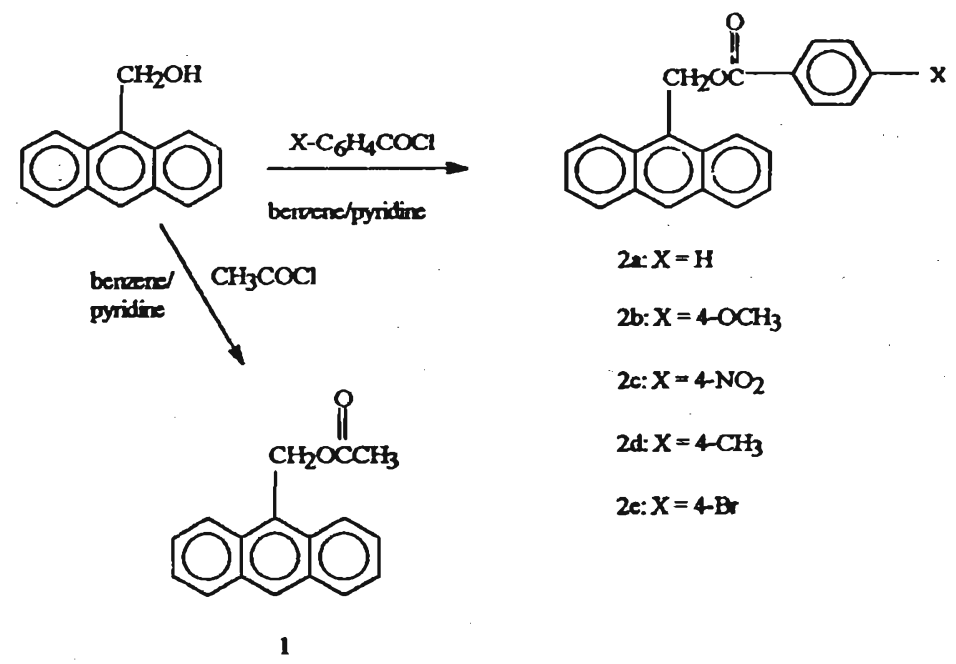

$$
\begin{aligned}
& 2 \mathrm{a}: X=\mathrm{H} \\
& 2 \mathrm{~b}: X=4 \mathrm{OCH}_{3} \\
& 2 \mathrm{c}: X=4-\mathrm{NO}_{2} \\
& 2 \mathrm{~d}: X=4 \mathrm{CH}_{3} \\
& 2 \mathrm{e}: X=4 \mathrm{Br}
\end{aligned}
$$

Scheme 1: Preparation of Esters 1 and 2a-e.

To a solution of alcohol ( $10 \mathrm{mmol})$ in $50 \mathrm{ml}$ of benzene and $1 \mathrm{ml}$ of pyridine, a solution of acid chloride ( $12 \mathrm{mmol}$ ) in $20 \mathrm{ml}$ of benzene was added. After leaving overnight, the mixture was poured into $50 \mathrm{ml}$ of water and the organic layer separated. This layer was dried and evaporated to give an oil or solid. This crude product was chromatographed on silica gel with $30 \%$ dichloromethane:hexane as eluent. 
9-anthracenemethyl acetate, $1: \mathrm{mp}=90-92{ }^{\circ} \mathrm{C},{ }^{1} \mathrm{H} \mathrm{nmr}\left(\mathrm{CDCl}_{3}\right) \delta: 2.08(\mathrm{~s}, 3 \mathrm{H})$ $6.15(\mathrm{~s}, 2 \mathrm{H}), 7.35-7.58(\mathrm{~m}, 4 \mathrm{H}), 8.03(\mathrm{~d}, 2 \mathrm{H}, \mathrm{J}=4.5 \mathrm{~Hz}), 8.32(\mathrm{~d}, 2 \mathrm{H}, \mathrm{J}=4.5 \mathrm{~Hz}), 8.51(\mathrm{~s}, 1 \mathrm{H})$, IR $\left(\mathrm{CCl}_{4}\right) \mathrm{cm}^{-1}: 1732,1232,1209,790, \mathrm{GC} / \mathrm{MS}$ (m/e): 251(9), 280(52), 191(100), 190(20.25), 189(30), 179(19), 178(12), 176(8), 95(7).

9-anthracenemethyl benzoate, $2 \mathrm{a}: \mathrm{mp}=56-58^{\circ} \mathrm{C},{ }^{1} \mathrm{H} \mathrm{nmr}\left(\mathrm{CDCl}_{3}\right) \delta: 6.36(\mathrm{~s}, 2 \mathrm{H})$, 7.29-7.58(m,7H), 8.00-8.20(m,4H), 8.44(d,2H,J $=4 \mathrm{~Hz}), 8.54(\mathrm{~s}, 1 \mathrm{H}), \mathrm{IR}\left(\mathrm{CCl}_{4}\right) \mathrm{cm}^{-1}$ : 1713, 1258, 1101, 795, GC/MS (m/e): 312(74), 193(28), 192(22), 191(100), 190(24), 189(30), 179(9), 155(9), 105(42), 77(33).

9-anthracenemethyl-4 -methoxybenzoate, $2 \mathrm{~b}: \quad \mathrm{mp}=128-130^{\circ} \mathrm{C},{ }^{1} \mathrm{H}$ $n \operatorname{mr}\left(\mathrm{CDCl}_{3}\right) \delta: 3.8(\mathrm{~s}, 3 \mathrm{H}), 6.36(\mathrm{~s}, 2 \mathrm{H}) ; 6.83(\mathrm{~d}, 2 \mathrm{H}, \mathrm{J}=4.5 \mathrm{~Hz}), 7.49-7.58(\mathrm{~m}, 4 \mathrm{H})$, $7.95(\mathrm{~d}, 2 \mathrm{H}, \mathrm{J}=4 \mathrm{~Hz}), 8.05(\mathrm{~d}, 2 \mathrm{H}, \mathrm{J}=4 \mathrm{~Hz}), 8.44(\mathrm{~d}, 2 \mathrm{H}, \mathrm{J}=4 \mathrm{~Hz}), 8.54(\mathrm{~s}, 1 \mathrm{H}), \mathrm{IR}\left(\mathrm{CCl}_{4}\right)$ $\mathrm{cm}^{-1}: 1705,1258,1101,795$, GC/MS (m/e): 342(54), 192(20), 191(100), 190(26), 189(37), 179(11), 178(10), 105(38), 77(26), 51(13).

9-anthracenemethyl-4 -nitrobenzoate $2 \mathrm{c}: \mathrm{mp}=120-122^{\circ} \mathrm{C},{ }^{1} \mathrm{H} \mathrm{nmr}\left(\mathrm{CDCl}_{3}\right)$ $\delta: 6.47(\mathrm{~s}, 2 \mathrm{H}), 7.45-7.66(\mathrm{~m}, 6 \mathrm{H}), 8.04(\mathrm{t}, 2 \mathrm{H}, \mathrm{J}=8 \mathrm{~Hz}), 8.16(\mathrm{~d}, 2 \mathrm{H}, \mathrm{J}=4 \mathrm{~Hz})$, $8.42(\mathrm{~d}, 2 \mathrm{H}, \mathrm{J}=9 \mathrm{~Hz}), 8.58(\mathrm{~s}, 1 \mathrm{H}), \operatorname{IR}\left(\mathrm{CCl}_{4}\right) \mathrm{cm}^{-1}: 1718,1531,1272,1102,776 . \mathrm{GC} / \mathrm{MS}$ (m/e): 357(34), 192(20), 191(100), 167(51), 137(12), 121(25), 109(15), 76(22), $75(25), 74(20), 65(100), 53(15), 51(30)$.

9-anthracenemethyl-4 -methylbenzoate $2 \mathrm{~d}: \mathrm{mp}=131-132^{\circ} \mathrm{C},{ }^{1} \mathrm{Hnmr}\left(\mathrm{CDCl}_{3}\right)$ $\delta: 2.2(\mathrm{~s}, 3 \mathrm{H}) 6.36(\mathrm{~s}, 2 \mathrm{H}), 7.50-7.20(\mathrm{~m}, 6 \mathrm{H}), 8.00-7.80(\mathrm{~m}, 4 \mathrm{H}), 8.20(\mathrm{~d}, 2 \mathrm{H}, \mathrm{J}=4 \mathrm{~Hz})$, 8.45(s,1H), IR( $\left(\mathrm{CCl}_{4}\right) \mathrm{cm}^{-1}: 1720,1284,1101,776 . \mathrm{GC} / \mathrm{MS}(\mathrm{m} / \mathrm{e}): 326(10), 192(20)$, 191(100), 190(21), 179(12), 178(10), 105(32), 77(29), 51(18).

9-anthracenemethyl-4 -bromobenzoate $2 \mathrm{e}: \mathrm{mp}=74-75^{\circ} \mathrm{C},{ }^{1} \mathrm{H} \mathrm{nmr}\left(\mathrm{CDCl}_{3}\right) \delta$ : 6.34(s,2H), 7.50-7.82(m,8H), 8.05(d,2H,J=4Hz), 8.30(d,2H,J=4Hz), 8.44(s,1H), $\operatorname{IR}\left(\mathrm{CCl}_{4}\right) \mathrm{cm}^{-1}: 1716,1265,1108,786$. GC/MS (m/e): 390(5), 388(4), 192(22), 191(100), 190(28), 179(10), 105(38), 77(28), 51(15).

\section{RESULTS}

Absorption studies: The absorption spectra of $1 \times 10^{-5} \mathrm{~mol} \mathrm{dm}^{-3}$ solutions of the esters $\mathbf{1}$ and $\mathbf{2 a}$ - e in cyclohexane, dioxane, chloroform, dichloromethane, tetrahydrofuran, acetonitrile and methanol respectively were recorded at $25^{\circ} \mathrm{C}$. Nitrogen gas was bubbled through the solutions for $20 \mathrm{~min}$, prior to recording the spectra. The data are presented in Tables 1 and 2.

Fluorescence studies: The emission spectra of esters in the above solutions were recorded and the data are presented in Tables 1 and 2 . The samples were purged 
with $\mathrm{N}_{2}$ for 20 min before measurements were taken. The fluorescence quantum yields of esters 1 and 2a-e dissolved in methanol were determined using anthracene $\left(\phi_{f}=0.4\right)$ in methanol as the standard. The singlet state energies were determined by the position of the 0,0 band using the overlap between the emission and excitation spectra.

Table 1: The absorption ${ }^{a}\left(\lambda_{a}\right)$ and emission ${ }^{b}\left(\lambda_{e}\right)$ maxima of the compounds $1,2 a$ and $2 c$ in different solvents.

\begin{tabular}{|c|c|c|c|c|c|c|c|}
\hline \multirow[b]{2}{*}{ Solvent } & \multicolumn{2}{|c|}{1} & \multicolumn{2}{|c|}{$\mathbf{2 a}$} & \multicolumn{2}{|c|}{$2 c$} & \multirow[b]{2}{*}{${ }^{c} \mathrm{~F}$} \\
\hline & $\lambda_{\mathrm{a}}(\mathrm{nm})$ & $\lambda_{\mathrm{e}}(\mathrm{nm})$ & $\lambda_{\mathrm{a}}(\mathrm{nm})$ & $\lambda_{\mathrm{e}}(\mathrm{nm})$ & $\lambda_{\mathrm{a}}(\mathrm{nm})$ & $\lambda_{\mathrm{e}}(\mathrm{nm})$ & \\
\hline cyclohexane & 384.0 & 391.6 & 383.8 & 390.8 & 384.4 & 390.0 & -0.0026 \\
\hline dioxane & 385.5 & 394.0 & 385.2 & 393.6 & 385.3 & 394.8 & -0.0024 \\
\hline chloroform & 386.8 & 396.0 & 387.0 & 396.0 & 387.2 & 396.0 & 0.3706 \\
\hline dichloromethane & 386.2 & 396.0 & 385.8 & 396.0 & 385.9 & 396.4 & 0.5903 \\
\hline tetrahydrofuran & 385.2 & 393.2 & 385.0 & 392.8 & 385.1 & 396.8 & 0.5491 \\
\hline acetonitrile & 383.6 & 396.8 & 388.0 & 392.8 & 387.6 & 393.2 & 0.8593 \\
\hline methanol & 383.7 & 391.0 & 385.1 & 392.7 & 383.0 & 394.6 & 0.8237 \\
\hline
\end{tabular}

"The longest wavelength band maxima were taken.

"The shortest wavelength band maxima were taken.

'Values taken from reference number 13.

Determination of the dipole moment difference $\left(\mu_{e}-\mu_{g}\right)$ between the excited and ground state: The $\left(\mu_{\mathrm{e}}-\mu_{\mathrm{g}}\right)$ for the esters $\mathbf{1 , 2 \mathbf { b }}$ and $\mathbf{2 c}$ were determined by the method of solvatochromism. Bakshievs formula has been used in our studies:

$$
v_{\mathrm{a}}-v_{\mathrm{f}}=2 \mathrm{~F}\left(\mu_{\mathrm{c}}-\mu_{\mathrm{g}}\right) / \mathrm{h} \tau \mathrm{a}_{0}^{3}
$$

where $v_{a}$ and $v_{f}$ are respectively the absorption and emission maximum wave numbers in $\mathrm{cm}^{-1}, \mu_{\mathrm{e}}$ and $\mu_{\mathrm{g}}$ are the dipole moments of the ground and excited state respectively.

$$
\mathrm{F}=\left[(\mathrm{D}-1) /(\mathrm{D}-2)-\left(\mathrm{n}^{2}+2\right) /\left(\mathrm{n}^{2}+2\right)\right]\left(2 \mathrm{n}^{2}+1\right) /\left(\mathrm{n}^{2}+2\right)
$$

where $\mathrm{D}$ is the dielectric constant of the solvents and $\mathrm{n}$ is the refractive index of the solvent. 


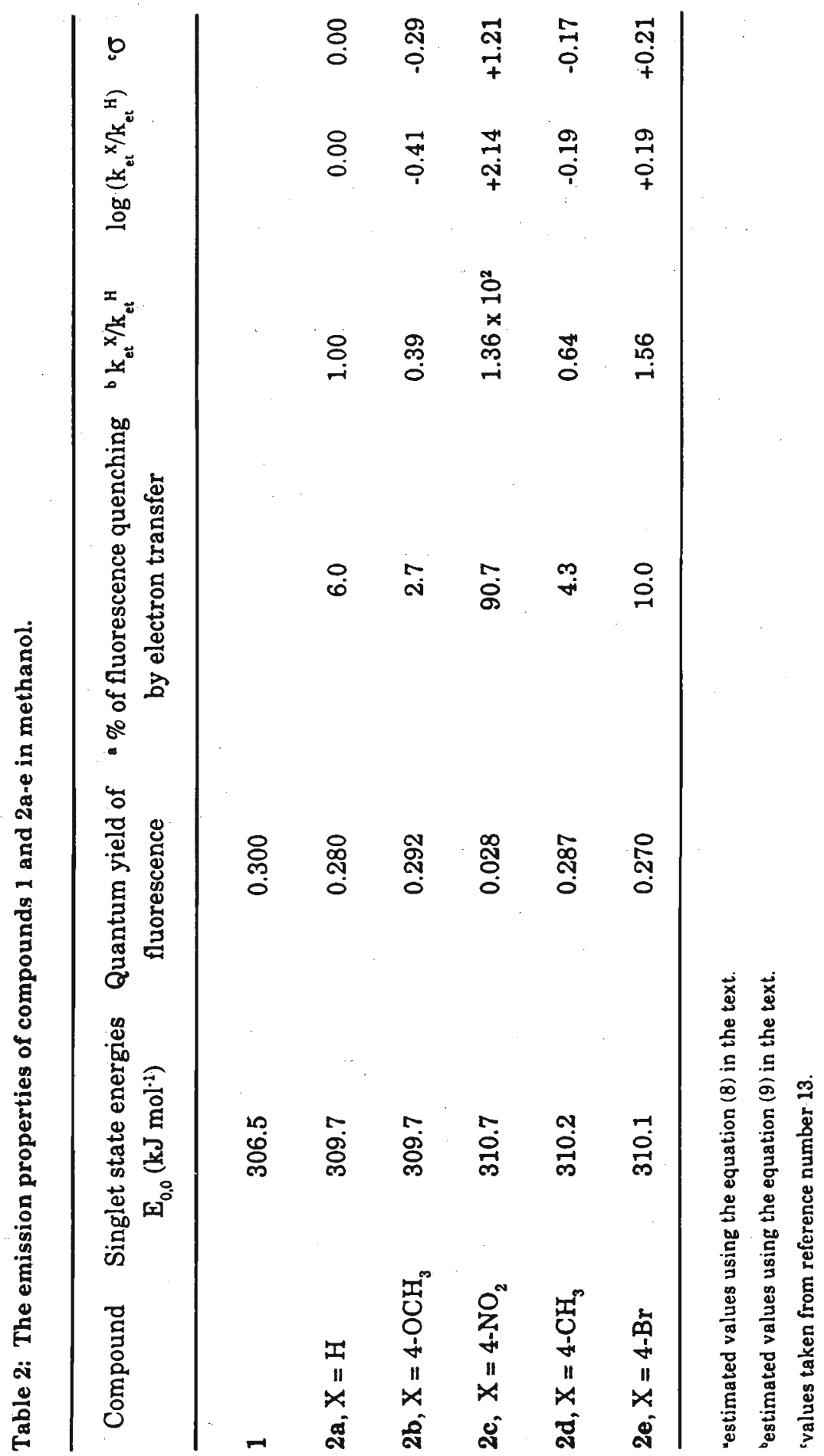




\section{DISCUSSION}

The solute-solvent properties and solvent polarity functions are shown in Table 1. The dielectric constant and the refractive indices of solvents at $25^{\circ} \mathrm{C}$ are taken from the literature. ${ }^{11}$ Figure 1 shows correlation between the solvent shifts and the solvent polarity function $F$ for the esters $1,2 \mathbf{b}$ and $2 \mathrm{c}$. Statistical treatment of the correlation of solvent spectral shifts for the esters have been performed for all the solvents. Solvents such as dioxane, acetonitrile and methanol show deviation from the Bakshievís correlation. By eliminating these solvents, the slope of the Stokes shift versus $F$ were calculated as $1.27,1.55$ and 1.93 for the compounds 1, 2a and 2c. From these values it is clear that there is s charge separation in these esters when they are in the excited states. Also the charge separation is higher for $2 \mathrm{c}$ than for $\mathbf{2 a}$. This suggests that the charge transfer is more in compound $\mathbf{2 c}$ than in $\mathbf{2 a}$.

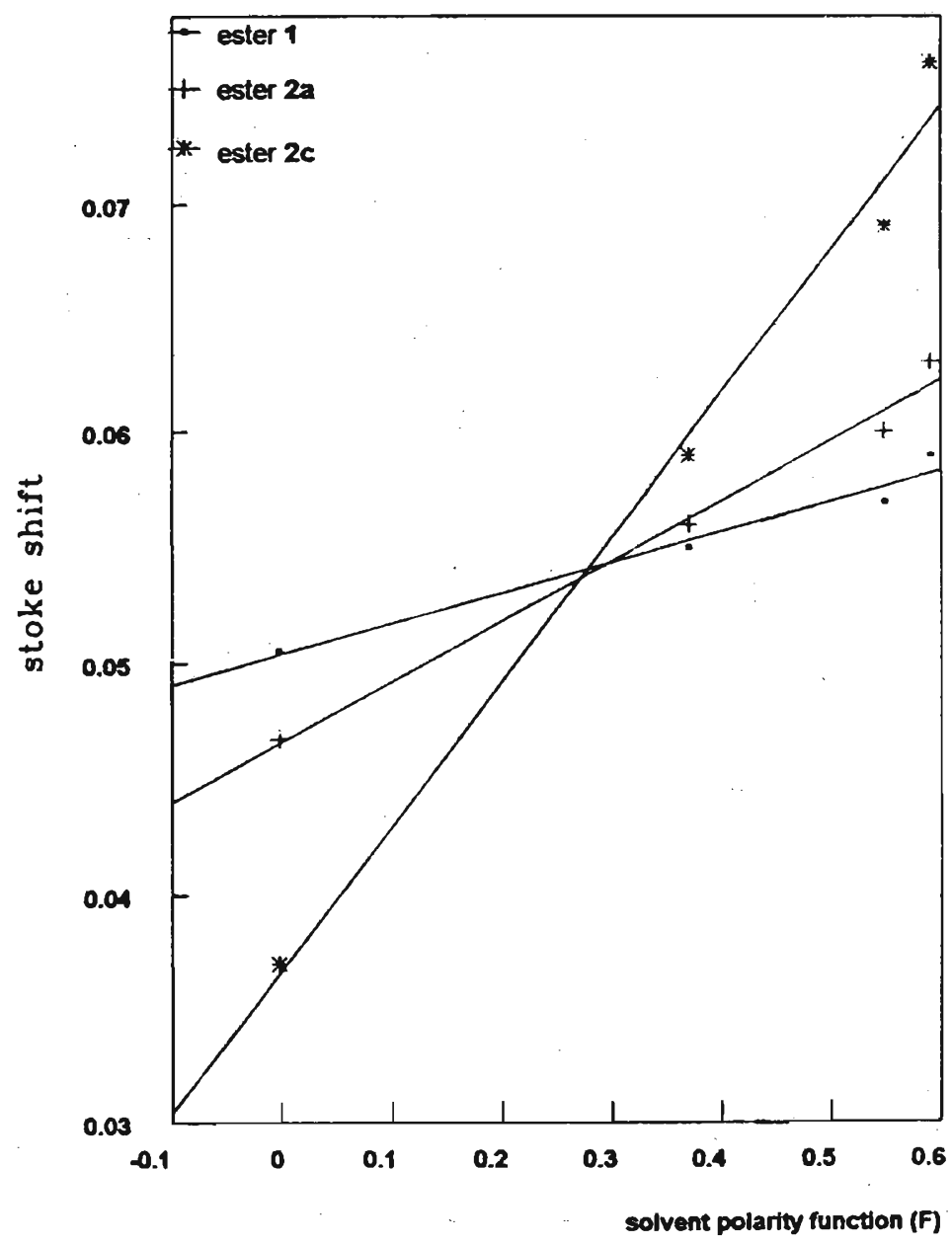

Figure 1: Bakshiev's correlation between the Stoke shifts and the solvent polarity function (F) for esters $1,2 a$ and $2 c$. 
As mentioned in the introduction the lower fluorescence quantum yield of 1-naphthyl methyl benzoate esters were due to the intramolecular electrontransfer from the naphthalene chromophore to the benzoate chromophore. Table 1 shows the change of fluorescence quantum yield of 2 in methanol with different substituents on the benzoate chromophore. According to the Wellar equation (equation 1), the energy of the electron transfer is dependent on the oxidation potential of the electron donor and reduction potential of the electron acceptor. The electron withdrawing groups on the benzoate chromophore, $2 \mathrm{c}$ and $\mathbf{2 e}$, show lower fluorescence quantum yields, supporting the intramolecular electron-transfer from anthracene chromophore to the benzoate chromophore. For instance, the free energy of the electron transfer process for compound $2 \mathrm{a}$ has been calculated as $-320 \mathrm{~kJ} \mathrm{~mol}^{-1}$ by using Weller equation along with the oxidation potential of anthracene $(-1.82 \mathrm{~V}$ wrt SCE $),{ }^{7}$ reduction potential of methyl benzoate $(2.12 \mathrm{~V} \text { wrt SCE })^{12}$ and singlet state energy of $309.7 \mathrm{~kJ} \mathrm{~mol}^{-1}$. The negative value for the free energy of the electron transfer indicates that the process is feasible. The lowering of fluorescence quantum yields in benzoate compared to that of acetate can be explained by the electron transfer process. The electron withdrawing group on the benzoate chromophore, in esters $2 \mathbf{c}$ and $\mathbf{2 e}$, gives a lower reduction potential. This enhances the intramolecular electron transfer rates lowering the fluorescence quantum yields compared to that of unsubstituted 2a. On the other hand the electron donating substituents on the benzoate ring, in esters $\mathbf{2 b}$ and $\mathbf{2 d}$, increase the reduction potential making the electron transfer less favourable. This results in an increase in the fluorescence quantum yields when compared to that of unsubstituted ester $2 \mathbf{a}$.

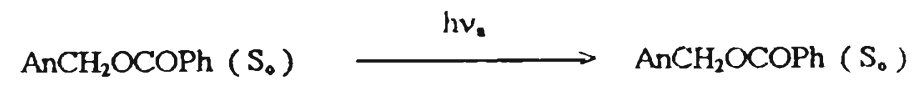

$\mathrm{AnC} \mathrm{H}_{2} \mathrm{OCOPh}\left(\mathrm{S}_{1}\right) \longrightarrow \mathrm{k}_{\mathrm{f}} \longrightarrow \mathrm{AnCH}_{2} \mathrm{OCOPh}\left(\mathrm{S}_{0}\right)+h v_{\mathrm{f}}$

$\operatorname{AnCH} \mathrm{OCOPh}_{2}\left(\mathrm{~S}_{1}\right) \longrightarrow \mathrm{k}_{\mathrm{ise}} \longrightarrow \operatorname{AnCH}_{2} \mathrm{OCOPh}\left(\mathrm{T}_{1}\right)$

$\mathrm{AnCH} \mathrm{OCOPh}_{\left(\mathrm{S}_{1}\right)} \longrightarrow \mathrm{k}_{\mathrm{ie}} \longrightarrow \mathrm{AnCH}_{2} \mathrm{OCOPh}\left(\mathrm{S}_{6}\right)$

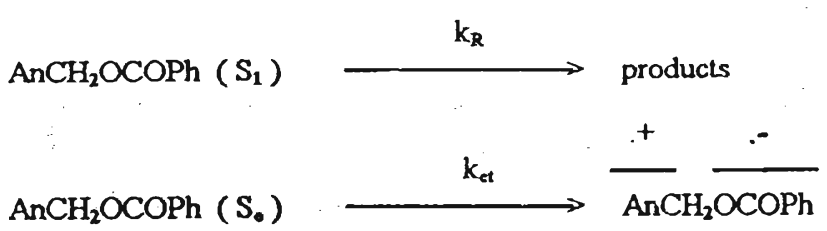

Scheme 2: Mechanism for the irradiation of 9-anthracenemethyl benzoate in methanol. 
The mechanism outlined in the Scheme 2, can be used for the quantitative explanation of the results. According to the mechanism there are five different pathways for the disappearance of the excited state. $S_{1}$ of the benzoate esters with rate constants $\mathrm{k}_{\mathrm{f}}, \mathrm{k}_{\mathrm{isc}}, \mathrm{k}_{\mathrm{ic}}, \mathrm{k}_{\mathrm{R}}$ and $\mathrm{k}_{\mathrm{et}}$. The following equation can be easily derived for the quantum yield of fluorescence of benzoate ester using the steady state conditions:

$\phi_{f}^{B}=\frac{k_{f}}{k_{f}+k_{I S C}+k_{I C}+k_{R}+k_{e t}}$

The fluorescence quantum yield for ester $\mathbf{1}$, can be given as follows:

$\phi_{\mathrm{f}}^{\mathrm{A}}=\frac{\mathrm{k}_{\mathrm{f}}^{0}}{\mathrm{k}_{\mathrm{f}}^{0}+\mathrm{k}_{\mathrm{ISC}}{ }^{0}+\mathrm{k}_{\mathrm{IC}}{ }^{0}+\mathrm{k}_{\mathrm{R}}{ }^{0}+\mathrm{k}_{\mathrm{et}}{ }^{o}}$

making the reasonable assumption that the rates of disappearance of the excited state of the acetate and benzoate esters are similar except for the difference in the rate of electron transfer.

Since there is no intramolecular electron transfer for the acetate, one can derive the equations (5) and (6).

$\frac{\phi_{\mathrm{f}}^{\mathrm{A}}}{\phi_{\mathrm{f}}^{\mathrm{B}}}=1+\tau \mathrm{k}_{\mathrm{et}}$

$\phi_{\text {et }}=1-\frac{\phi_{f}^{\mathrm{B}}}{\phi_{\mathrm{f}}^{\mathrm{A}}}$

Here $\tau=\mathrm{k}_{\mathrm{f}}{ }^{0} / \mathrm{k}_{\mathrm{f}}{ }^{0}+\mathrm{k}_{\mathrm{ISC}}{ }^{0}+\mathrm{k}_{\mathrm{IC}}{ }^{0}+\mathrm{k}_{\mathrm{R}}{ }^{0}+\mathrm{k}_{\mathrm{et}}{ }^{0}=\mathrm{k}_{\mathrm{f}} / \mathrm{k}_{\mathrm{f}}+\mathrm{k}_{\mathrm{ISC}}+\mathrm{k}_{\mathrm{IC}}+\mathrm{k}_{\mathrm{R}}$, is the lifetime of the acetate ester and is a constant.

From equation (5),

$$
\left(\frac{\phi_{\mathrm{f}}^{\mathrm{A}}}{\phi_{\mathrm{fB}}}-1\right) \alpha \mathrm{k}_{\mathrm{et}}
$$


From equation (6), the percentage of fluorescence quenching in the substituted benzoate esters can be expressed as,

The percentage of Fluorescence quenching $=\left(1-\frac{\phi_{\mathrm{f}}^{\mathrm{B}}}{\phi_{\mathrm{f}}^{\mathrm{A}}}\right) \times 100$

The values for the percentage of quenching of fluorescence by intramolecular electron-transfer can be estimated by equation (8) and are given in Table 2 . The variation of percentage of quenching of the fluorescence with the Hammett $\sigma^{13}$ values is given in Figure 2.

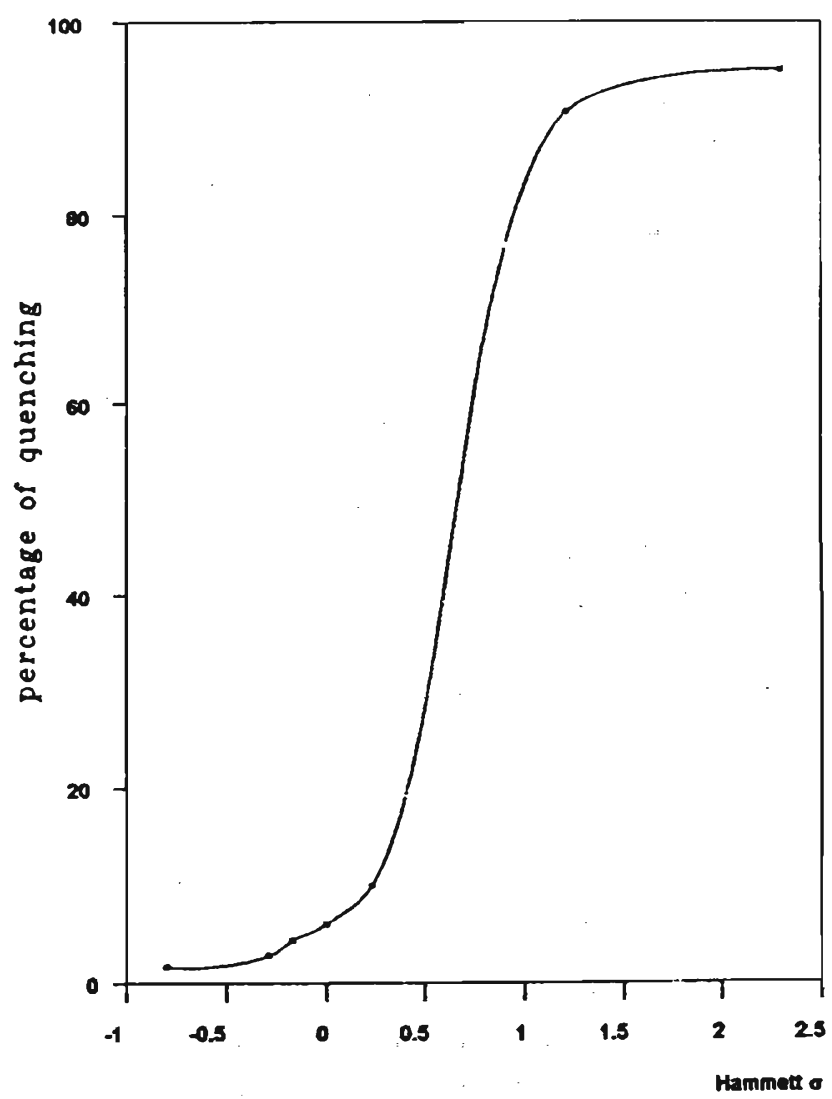

Figure 2: Plot between percentage of quenching and Hammett $\sigma$.

Taking the electron transfer rates for unsubstituted and substituted esters as $\mathrm{k}_{\mathrm{et}}{ }^{\mathrm{H}}$ and $\mathrm{k}_{\mathrm{et}}{ }^{\mathrm{X}}$ respectively and using the equation (7), one can derive:

$$
\left(\frac{\phi_{f}^{A}}{\phi_{f}^{B}}-1\right)_{X} /\left(\frac{\phi_{f}^{A}}{\phi_{f}^{B}}-1\right)_{H}=k_{e t}{ }^{{ }^{X}} / k_{e t}{ }^{H}
$$


According to the Hammett linear free energy relation (LFER), ${ }^{14}$

$\log \left(\mathbf{k}_{\mathrm{et}}{ }^{\mathrm{X}} / \mathrm{k}_{\mathrm{et}}{ }^{\mathrm{H}}\right)=\rho \sigma$

where the $\rho$ and $\sigma$ are the reaction constant and the substituents constants respectively.

The values for the above equation are given in Table 3. The $\log \left(\mathrm{k}_{\mathrm{et}}{ }^{\mathrm{x}} / \mathrm{k}_{\mathrm{et}}{ }^{\mathrm{H}}\right)$ were plotted against the reaction constant, $\sigma$ and a linear plot was obtained as given in Figure 3.

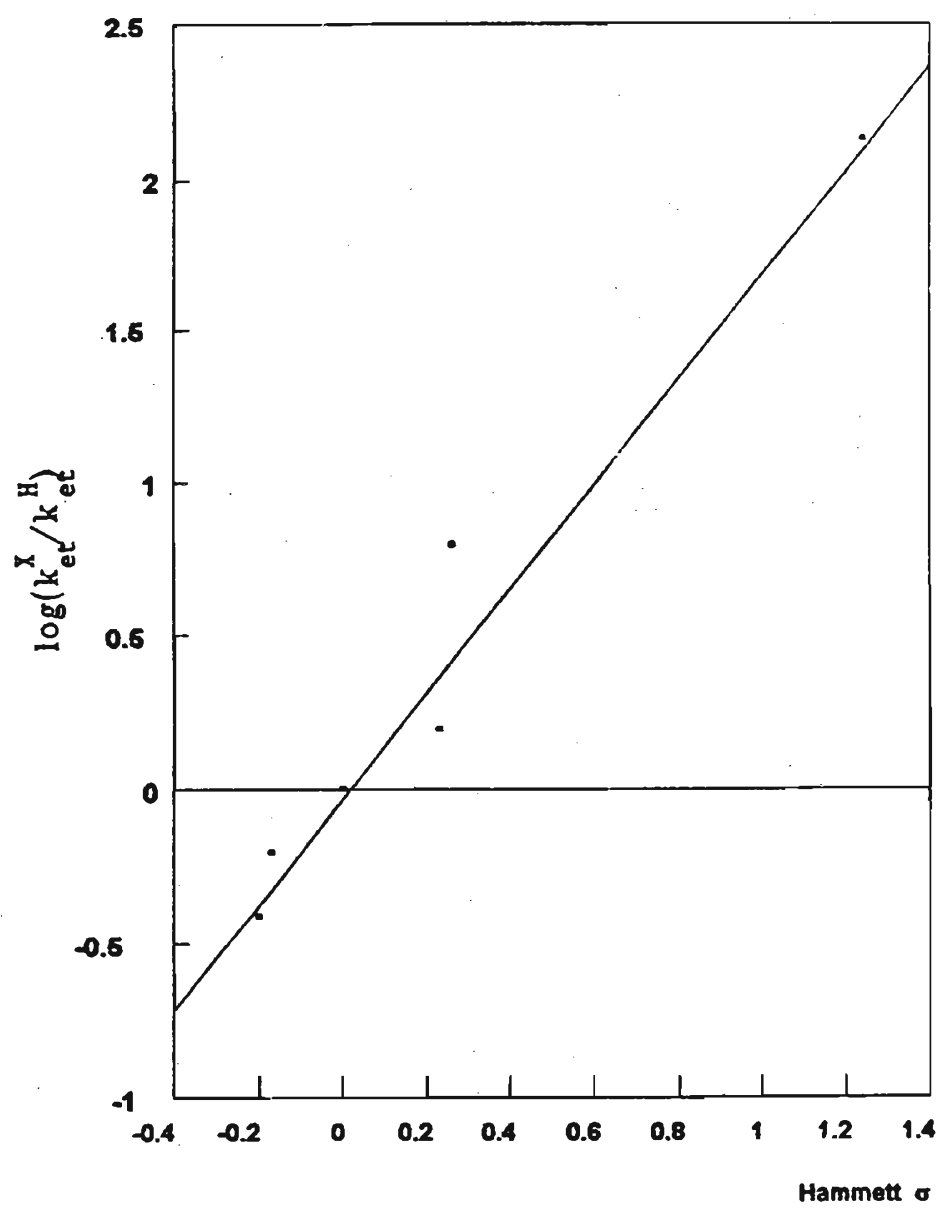

Figure 3: $\log \left(k_{e t}{ }^{x} / k_{e t}{ }^{H}\right)$ versus Hammett $\sigma$.

A straight line suggests the validity of the proposed mechanism although alternatives are not completely ruled out. The $-\mathrm{CH}_{2} \mathrm{OCO}$ - linkage between the anthracene chromophore and benzene chromophore gives an efficient overlapping of the orbitals. The s-cis configuration is necessary for the efficient 
overlapping of the orbitals. The linear plot between the $\mathrm{k}_{\mathrm{et}} \mathrm{x} / \mathrm{k}_{\mathrm{ct}}{ }^{\mathrm{H}}$ and $\sigma$ is very good evidence for the overlapping of the orbitals of the anthracene and benzoate chromophores and hence intramolecular electron transfer from the one to the other. The reaction constant $\rho$ is calculated as 1.53. The electron-transfer takes place from the excited state surface. Therefore the substituents have very little effect on the absorption spectra However, the emission spectra will be greatly affected by a variation of the substituent. Indeed, the electron-transfer is the controlling factor for the fluorescence quantum efficiencies. High $\rho$-values ( $\rho>1$ ) are frequently reported for the ionisation reactions in which the developing charge is in direct conjugation with the substituent on the aromatic ring. Indeed, direct conjugation would be better modelled by Okomota ${ }^{15} \sigma$ relationships. The $\rho$-values higher than 4.0 are reported ${ }^{17}$ and these higher values were explained by the direct conjugations.

In this study we attempted LFER correlations with $\sigma$ and $\sigma$. Our best fit is with Hammett $\sigma$, which gave $\rho$-value of $+1.5(r=98.9 \%)$ for $k_{\text {et }}$. This suggests that the electron-transfer from the anthracene chromophore to the benzoate chromophore takes place with some charge delocalization into the benzene ring.

\section{Acknowledgement}

We thank the, University of Colombo, for financial support given (grants 95/s/ 11 and 96/s/11). KADSM thanks the Prof. W.P.D. Pereira scholarship fund for her fellowship.

\section{References}

1. Balzani V., Bolletla F., Gandolfi M.J. \& Maestri M. (1978). Excited states redox reactions. Topics in Current Chemistry 75: 1-64.

2. Fox M,A. \& Chanon M. (1988). Photoinduced electron transfer, volumes AD. Elsevier, Amsterdam.

3 Cho D.W., Kim Y.H., Kang S.G.,Yoon M., \& Kim D. (1996). Cyclodextrien Effects on intramolecular charge transfer of 2-biphenyl carboxylic acids. Journal of Chemical Society, Faraday Transaction 92(1): 29-32.

4. Bakshiev N.G. (1962). Solvent dielectric relaxation effects. Optical Spectroscopy 13: 507-530.

5. Kawski A. (1994). Progress in photochemistry and photophysics, Volume V, CRC press, USA. 
6. Hirayama F. (1965). Energy transfer and quenching in plastic sensitizers. Journal of Chemical Physics 42: 3163-3165.

7. Wang H., Zhang B.W. \& Cao Y. (1995). Intramolecular charge transfer and exciplex formation in anthracene bichromophoretic compounds. Journal of Photochemistry and Photobiology A: Chemistry 92: 29-35.

8. Iwamura M. Tokuda K., Koga N. \& Iwamura H. (1988). Intramolecular charge transfer and exciplex formation of 1-pyrene methyl esters of carboxylic acids. Chemical Letters 1249-1251.

9. de Costa D. P. \& Pincock J.A. (1993). Intramolecular charge transfer in the photochemistry of substituted 1-naphthylmethyl esters of benzoic acid. Canadian Journal of Chemistry 42: $2872-2879$.

10. Rehm D. \& Wellar A. (1970). Kinetics of fluorescence quenching by electron and hydrogen transfer. Israelian Journal of Chemistry 8: 259-269.

11. Rani S.A., Sobhanadi J. and Rao J.A.P. (1995). Determination of the excited state dipole moment of fluorenone using the method of solvalochromism. Spectrochemica Acta Part A, 51: 2473-2481.

12. Eberson L. (1987). Electron transfer in organic chemistry, pp. 45-62, SpringVerleg, New York.

13. Isaacs N.S. (1987). Physical organic chemistry, pp. 134-135, Longman, United Kingdom.

14. Hammett L.P. (1935) Linear free energy relationships. Chemical Reviews 17: $225-235$.

15. Okamota Y., Inukai T. \& Brown H.C. (1958). Rates of solvolysis of substituted phenyldimethylcarbonyl chloride in methyl, ethyl and isopropyl alcohols: influence of the solvent on the value of the electrophilic substituents constant. Journal of American Chemical Society 50: 4792-4799. 